\title{
Correspondence
}

We welcome letters to the Editor concerning articles which have recently been published. Such letters will be subject to the usual stages of selection and editing; where appropriate the authors of the original article will be offered the opportunity to reply.

Letters should normally be under 300 words in length, double-spaced throughout, signed by all authors and fully referenced. The edited version will be returned for approval before publication.

\section{Radiation therapy for the prevention of heterotopic ossification at the elbow}

Sir,

I write to comment on the article in the April 2001 issue entitled 'Radiation therapy for the prevention of heterotopic ossification at the elbow' by Heyd et al. ${ }^{1}$ In this study, the authors have concluded that on the basis of their nine cases, perioperative radiation therapy should be used to avoid recurrence of heterotopic ossification (HO). They have not, however, provided any control group for comparison and hence no meaningful conclusions can be drawn. All the other studies which the authors have reviewed in this article, including that by McAuliffe and Wolfson, ${ }^{2}$ do not have any control group for comparison.

The role of radiation therapy in the prevention of recurrence of HO around the elbow remains anecdotal. There have been studies by Viola and Hanel, ${ }^{3}$ Jupiter and Ring ${ }^{4}$ and Denormandie et $\mathrm{al}^{5}$ which have demonstrated similar or better results without the use of radiation therapy. I therefore think that in the absence of a control group and of any conclusive evidence in the literature about the benefit of perioperative radiation therapy, the authors' conclusions about the role of such treatment are not convincing.

The title of the article is 'Radiation therapy for the prevention of heterotopic ossification at the elbow', but the authors have reviewed cases with established $\mathrm{HO}$ which were treated by surgical excision and radiotherapy. I think therefore that the title should have been 'Radiation therapy for the prevention of recurrence of heterotopic ossification at the elbow'.

They have not provided any details about the timing of surgical excision of HO, i.e., whether it was excised early or later. The timing is still controversial, with some investigators advocating a wait of one to two years before release and others advising early release.

M. AGARWAL, MS, FRCS

Darent Valley Hospital

Dartford, UK.

1. Heyd R, Strassman G, Schopohl B, Zamboglou N. Radiation therapy for the prevention of heterotopic ossification at the elbow. $J$ Bone Joint Surg [Br] 2001;83-B:332-4.

2. McAuliffe JA, Wolfson AH. Early excision of heterotopic ossification about the elbow followed by radiation therapy. J Bone Joint Surg [Am] 1997;79-A:749-55.

3. Viola RW, Hanel DP. Early 'simple' release of post-traumatic elbow contracture associated with heterotopic ossification. J Hand Surg [Am] $1999 ; 24: 370-80$.

(C)2001 British Editorial Society of Bone and Joint Surgery

0301-620X/02/213135 \$2.00

J Bone Joint Surg [Br] 2002;84-B:305-8.
4. Jupiter JB, Ring D. Operative treatment of post-traumatic proximal radioulnar synostosis. J Bone Joint Surg [Am] 1998;80-A:248-57.

5. Denormandie P, Viguie G, Denys P, Dizien O, Carlier R. Results of excision of heterotopic new bone around the elbow in patients with head injuries: a series of 25 cases. Chir Main 1999;18:99-107.

Authors' reply:

Sir,

We thank Mr Agarwal for his interest in our paper.

Prophylactic radiotherapy (RT) for the prevention of heterotopic ossification $(\mathrm{HO})$ is widely used in patients who undergo total hip replacement, but at other sites its role is controversial. Because of this we were not able to provide data from a control group and no prospective randomised trials have recently been reported as shown by the review of the literature given in Table III of our paper. By contrast, for patients undergoing total hip replacement, the beneficial effect of $\mathrm{RT}$ in comparison with a control group has been demonstrated.

Concerning the timing of the surgical excision we followed the recommendations of Garland. ${ }^{2}$ In the seven patients with posttraumatic $\mathrm{HO}$ and in the other with spontaneous development of $\mathrm{HO}$, the bone was excised six to eight months after diagnosis. In the patient with neurogenic $\mathrm{HO}$ after cerebral bleeding the surgical procedure was performed 12 months after the injury.

The beneficial effect of RT for the prophylaxis of $\mathrm{HO}$ has been demonstrated and systematically investigated in patients undergoing total hip replacement, but we agree with Mr Agarwal that clinical studies providing results from a control group are necessary in order to define the risk group in which prophylactic RT at the elbow is indicated. The timing of the surgical excision of persisting $\mathrm{HO}$ and of surgical stabilisation of fractures of the elbow are prognostic factors. Ilahi, Strausser and $\mathrm{Gabel}^{3}$ suggested that patients in whom the delay between elbow injury and surgical stabilisation is more than 48 hours may benefit from prophylaxis for $\mathrm{HO}$.

R. HEYD, MD

Klinikum Offenbach

Offenbach, Germany.

G. STRASSMANN, MD

University Hospital

Marburg, Germany.

1. Linclau L, Doktor G, Debois JM, Gutwirth P. Radiation therapy to prevent heterotopic ossification in cementless total hip arthroplasty. Acta Orthop Belg 1994;60:220-4.

2. Garland DE. A clinical perspective on common forms of acquired heterotopic ossification. Clin Orthop 1991;263:13-29.

3. Ilahi OA, Strausser DW, Gabel GT. Post-traumatic heterotopic ossification about the elbow. Orthopedics 1998;21:265-8.

\section{Excision of hemivertebrae in the management of congenital scoliosis}

Sir,

The article published in the May 2001 issue by Deviren et al ${ }^{1}$ entitled 'Excision of hemivertebrae in the management of congenital scoliosis involving the thoracic and thoracolumbar spine' is of considerable interest.

The authors are to be congratulated on their results, with a 
mean correction of $59 \%$ and a mean length of follow-up of 78.5 months. We note that the senior author (DSB) has published previously on the treatment of fully segmented lumbar hemivertebrae. ${ }^{2}$ The additional risk in operating above the conus for the thoracic and thoracolumbar hemivertebrae is important. One of our concerns was the mean age at surgery (13.4 years, range 6 to 19 years). The natural history of congenital scoliosis predicts that for untreated curves beyond the age of ten years, $64 \%$ to $84 \%$ of patients will have curves exceeding $40^{\circ} .{ }^{3-5}$ Seven of the ten patients described had previously undergone a posterior spinal fusion and then had further surgery to excise hemivertebrae. There is no mention of how these patients fared after posterior spinal fusion. It must be presumed that these curves progressed because of further anterior growth, necessitating the excision of hemivertebrae. Are the authors advocating initial posterior spinal fusion followed by a definitive excision of hemivertebrae in the management of congenital scoliosis?

It is now possible to diagnose many of these hemivertebrae from an antenatal ultrasound examination at 20 weeks. ${ }^{5}$ This early diagnosis allows close observation and in Nottingham we now advocate very early surgery for those curves showing documented progression and those which exceed a Cobb angle of $40^{\circ}$. We have operated on six such patients from 20 diagnosed on antenatal scans. We routinely use spinal cord monitoring (SSEP) during surgery. In three we performed anterior and posterior convex hemiepiphysiodesis and in five one-stage posterior resection of hemivertebrae with correction. The mean age at surgery was 14.4 months. The results have been very encouraging. ${ }^{6}$ We feel that early surgery is justifiable in such cases to avoid relentless progression and the appearance of significant secondary structural curves.

B. J. FREEMAN, FRCS Orth

J. A. OULLET, FRCS C

J. K. WEBB, FRCS

Queen's Medical Centre

Nottingham, UK.

1. Deviren V, Berven S, Smith JA, et al. Excision of hemivertebrae in the management of congenital scoliosis involving the thoracic and thoracolumbar spine. J Bone Joint Surg [Br] 2001;83-B:496-500.

2. Bradford DS, Boachie-Adjei O. One stage anterior and posterior hemivertebral resection and arthrodesis for congenital scoliosis. $J$ Bone Joint Surg [Am] 1990;72-A:536-40.

3. McMaster MJ, Ohtsuka K. The natural history of congenital scoliosis: a study of two hundred and fifty one patients. J Bone Joint Surg [Am] 1982;64-A:1128-47.

4. Winter RB, Moe JH, Eilers VE. Congenital scoliosis: a study of 234 patients treated and untreated. Part 1: natural history. J Bone Joint Surg [Am] 1968;50-A:1-15.

5. Winter RB, Moe JH, Eilers VE. Congenital scoliosis: a study of 234 patients treated and untreated. Part II: treatment. J Bone Joint Surg [Am] 1968;50-A:15-47.

6. Freeman BJ, Ouellet JA, Twining P, Webb JK. Antenatal diagnosis of foetal hemivertebrae. Presented at the British Scoliosis Society, Edinburgh, 7-9 March, 2001.

\section{Author's reply:}

\section{Sir,}

We thank Mr Freeman and colleagues for their interest in our article on hemivertebral excision for the management of congenital scoliosis.

There is no simple operation which can be performed for all congenital deformities. The success of surgery depends on choosing the right procedure at the right time. The best results of prophylactic hemiepiphysiodesis or early spinal arthrodesis have been shown in the younger age group with mild curves. The use of a convex hemiepiphysiodesis has not been a reliable technique for the correction of deformity in the past, but may be more reliable in patients under five years of age with curves which show progression. Unpredictable results are a disadvantage of these operations and further surgical treatment may be required.

Salvage procedures are necessary for patients who present at later stages with greater deformity with or without previous operative treatment which requires correction. In our series seven of the ten patients had undergone posterior spinal fusion elsewhere for progressive deformity related to a hemivertebra at the thoracic level. These patients all went on to progression of deformity and decompensation which indicates that a posterior arthrodesis is not effective for management of this deformity. We certainly do not advocate an initial posterior arthrodesis for patients with congenital scoliosis because of hemivertebrae at the thoracic level and reiterate our conclusion that a hemivertebral excision is the most reliable technique for correction of the deformity.

In our series, the mean age at surgery was 13.4 years (6 to 19) since most of these operations were revision procedures. The optimal timing of resection of a hemivertebra remains unresolved. We agree with Mr Freeman and his colleagues that early diagnosis and close observation are mandatory in the management of congenital scoliosis to avoid relentless progression.

\section{DEVIREN, MD}

University of San Francisco

San Francisco, USA.

\section{The Lubinus patellofemoral arthroplasty: a five- to ten-year prospective study}

Sir,

At a meeting of our journal club we read with interest the paper by Tauro et $\mathrm{al}^{1}$ in the July 2001 issue entitled 'The Lubinus patellofemoral arthroplasty'.

First, we would welcome the authors' comments on their findings at arthrotomy through an upper medial parapatellar incision in assessing the tibiofemoral joint. Were any arthroscopic findings taken into account, or were clinical and radiological findings used only to determine the degree of osteoarthritis in the rest of the joint, and what were the intraoperative findings?

Secondly, are we looking at the learning curves of all the surgeons involved or are the results a function of the design and instrumentation of the prosthesis? We observed the placement of the implant on the radiographs in the article with medial translation of the femoral component and varus angulation of approximately $6^{\circ}$, and we wonder whether or not placement of the component is the major problem and difficulty with this prosthesis. Also with regard to Figure 6 how long after the operation was this radiograph taken?

S. COLERIDGE, MRCS

Secretary of Orthopaedic Journal Club

Princess Royal Hospital

Haywards Heath, UK.

1. Tauro B, Ackroyd CE, Newman JH, Shah NA. The Lubinus patellofemoral arthroplasty: a five- to ten-year prospective study. $J$ Bone Joint Surg [Br] 2001;83-B:696-701.

\section{Authors' reply:}

Sir,

We thank Mr Colderidge for his letter. We were delighted to learn that our article was being discussed at their journal club.

It is important to establish the integrity of the tibiofemoral joint before proceeding to an isolated patellofemoral arthroplasty. 
Patients are first screened by standing anteroposterior and standing lateral views which give good information about the integrity of the tibiofemoral joint. Merchant's tangential view of the patellofemoral joint is included. Younger patients and those with earlier disease may well have had a preliminary arthroscopy for both diagnosis and treatment. Most of our patients had advanced isolated patellofemoral arthritis. MRI may also be used to establish the integrity of the tibiofemoral joint. ${ }^{1}$ This was not done routinely in our patients.

The final assessment was carried out at arthrotomy. It is possible to determine the integrity of the medial and lateral compartments without extending the deep incision distal to the level of the medial meniscus. Isolated chondral defects less than $1 \mathrm{~cm}$ in diameter were accepted provided that the menisci, cruciates and the rest of the articular surfaces were satisfactory. They were treated by a localised chondrectomy. Experience has shown that if there is generalised attrition of the articular cartilage of either the medial or lateral condyles, particularly in the elderly, then it is probably wiser not to perform an isolated patellofemoral arthroplasty.

Intraoperative assessment of tracking was performed in all patients and considered to be satisfactory at the end of the procedure. This was carefully assessed by the "no-thumb technique'. If there was any tendency for medial lift-off throughout the range of movement then we performed a full lateral release. We now believe that the soft-tissue releases should include the lateral patellofemoral ligament or fold close to its attachment to the femur and the lateral retinaculum, where it attaches to the lateral border of the patella (a peripatellar release). It is usually contracted in this area at the site of the lateral osteophyte. Extensive release from the lateral patellar border prevents the need for a mid-lateral release with all its soft-tissue consequences.

Appropriate soft-tissue releases are of paramount importance in isolated patellofemoral replacement. Some of our failures are probably due to surgical technique or as you suggest a learning curve. We believe, however, that there is an inherent problem with the femoral component which prevents optimal placement and alignment as detailed in our reply to Mr Roche. Figures 5 and 6 were both obtained five years after operation.

\section{E. ACKROYD, FRCS}

J. H. NEWMAN, FRCS

Avon Orthopaedic Centre

Bristol, UK.

1. Sharp I, Tyrrell PNM, White SH. Magnetic resonance imaging assessment for unicompartmental knee replacement: a limited role. The Knee 2001;8:213-8.

Sir,

The article by Tauro et al $^{1}$ in the July 2001 issue entitled 'The Lubinus patellofemoral arthroplasty' raises some important issues.

Since it is anatomical, the femoral component is not endorsed for use in the contralateral knee or to counteract a problem of softtissue maltracking which is regarded by some as a reason for not proceeding to patellofemoral arthroplasty. ${ }^{2}$ Persistent postoperative maltracking implies surgical error. Quoted progression of disease in the tibiofemoral joint is also not a complication.

The analysis of a heterogenous group as presented is invalid. No mention is made of the primary surgeon and whether a tourniquet was used routinely ${ }^{3}$ and details of the results of the subgroup with lateral releases may have been useful. What is the validity and responsiveness of the Bristol Knee Score to anterior knee pain, particularly as at least one patient with a good score (81) was selected for surgery?
The title should perhaps have been 'Reversal of the femoral component without proper selection and attention to maltracking has a chance of mid-term failure'. The authors' suspicions may well be correct regarding this implant but it is unfortunate that no other centres have yet published their results. Only then can we really make any progress in developing the ideal implant and refining our selection criteria.

\section{R. ROACH, FRCS}

North Staffs Royal Infirmary

Stoke-on-Trent, UK

1. Tauro B, Ackroyd CE, Newman JH, Shah NA. The Lubinus patellofemoral arthroplasty: a five- to ten-year prospective study. $J$ Bone Joint Surg [Br] 2001;83-B:696-701.

2. Lomer J. Patellofemoral arthroplasty. Seminars in arthroplasty, Volume 11, No. 4, October 2000.

3. Marson BM, Tokish JT. The effect of a tourniquet on the intraoperative patellofemoral tracking during total knee arthroplasty. $J$ Arthroplasty 1999;14:197-9.

\section{Authors' reply:}

Sir,

We thank Mr Roach for his interest in our article.

The Lubinus trochlear component is indeed anatomical, but has been designed to fit a normal trochlea. Most cases (80\%) in our series and in all published series had isolated patellofemoral arthritis predominantly affecting the lateral facet. This often causes major erosion not only of the patella but also of the lateral trochlea, considerably altering the anatomy. The Lubinus prosthesis fits the pathological anatomy poorly and for this reason it was often found that a better fit was obtained, and the tendency for patellar catching or jumping occurred less often when the opposite prosthesis was used. Approximately half of our patients had the prosthesis reversed and the results were better both for revision and pain although the follow-up was shorter.

In all series of isolated patellofemoral arthroplasties, maltracking is a common cause of failure and our series was no exception. All the operations were performed or supervised by the two consultant knee surgeons. A tourniquet was used and satisfactory tracking was recorded as having been obtained in all patients. Clearly, this was not always successful. It is increasingly recognised that the underlying anatomy of the patient may often lead to recurrence of maltracking with time. Similar problems have been encountered during total knee replacement and many systems now deliberately include three or more degrees of external rotation to aid patellar tracking. ${ }^{1}$ The same principle is desirable in the design of a trochlear component. Since the Lubinus component is anatomical, such an adjustment cannot be made. We agree that there are no other published results of the use of the Lubinus patellofemoral arthroplasty. The findings of Smith et $\mathrm{al}^{2}$ have been presented and are in press. Their results are similar to ours although with a considerably shorter follow-up.

We agree that the Bristol Knee Score is not specifically designed to assess anterior knee pain. The main indication for surgery is relief from pain which was used as an outcome criterion. The Bristol Pain Score has recently been shown to be a reliable system with an interobserver correlation coefficient of $0.8^{3}$. It has also been shown to be less influenced by the normal ageing process than some other commonly used systems.

Finally, the results of our experience of carrying out over 230 patellofemoral arthroplasties over the past 12 years has enabled us to refine our selection criteria and to make some progress in improving the design of the implant. The early results have been presented $^{5}$ and will be published in due course. The design and placement of the femoral trochlea are important.

The development of the soft-tissue releases should include the 
patellofemoral ligament and release of the retinaculum from the lateral edge of the patella (a peripatellar release) and its osteophyte to avoid the soft-tissue consequences of a midlateral release. We believe that correction of these aspects of tracking will considerably improve the results and the longevity of such prostheses.

C. ACKROYD, FRCS

J. H. NEWMAN, FRCS

Avon Orthopaedic Centre

Bristol, UK.

1. Newman JH, Ackroyd CE, Shah NA, Karachalios T. Should the patella be resurfaced during total knee replacement? The Knee 2000; 7:17-23

2. Smith AM, Peckett WRC, Butler-Manuel PA. Treatment of patellofemoral arthritis using the Lubinus patellofemoral arthroplasty. The Knee 2002;in press.

3. Bach CNM, Steingruber I, Nogler M, et al. Assessment of rating systems in total knee replacement. J Bone Joint Surg [Br] 2001;83-B:Suppl II, 244.

4. Bremmer-Smith A, Weale A. Knee scores in a normal elderly population. J Bone Joint Surg [Br] 2002;84-B:in press.

5. Ackroyd CE, Newman JH. The Avon patellofemoral arthroplasty: development and early results. J Bone Joint Surg $[\mathrm{Br}]$ 2001;83-B:Suppl II, 146-7.

\section{A prospective comparative analysis of mobility in osteoarthritic knees: does lifestyle have an influence?}

Sir,

We read with interest the article by Szabó et al in the November 2000 issue entitled 'A prospective comparative analysis of mobility in osteoarthritic knees: does lifestyle have an influence? ${ }^{1}$ We agree with the views of the authors. The restriction of knee movements in group 3 is probably due to an acquired contracture of rectus femoris. This can be clinically detected by testing the passive flexion of the knee in the prone position. The local life style in countries such as India, Nepal and Japan also requires activity at floor level in day-to-day life. This subjects rectus femoris to intermittent stretching which is essential for maintaining the range of full flexion of the knee. Since rectus femoris is the 'stem', it directly influences the performance of quadriceps and the range of knee movement. It is the only biarticular member of the quadriceps group, ${ }^{2}$ and by virtue of its dual fascial attachment acts effectively at both joints simultaneously. ${ }^{3}$ Physiological stretching of a muscle is necessary for full development. Even in a fully developed muscle in which the range of action is reduced for a period of time, the muscle fibres contract and shorten the length of the fasciculi to a point at which contraction amounting to about $57 \%$ of their newly acquired length is sufficient to bring about the required action. ${ }^{4}$ According to this rule, if rectus femoris is being stretched across the knee and hip in the kneeling position in day-to-day life, it maintains the power of quadriceps as well as the length, both of which contribute to the mobility of the knee. The other group of non-Muslims (group 3) is probably accustomed to a life style at chair level which does not stretch rectus to its efficient length. The radiological changes do not reflect the severity of symptoms which arise because of an acquired contracture of rectus femoris. Also, if the patient is subjected to daily passive stretching exercises in the same position, the range of movement and pain both improve, irrespective of the radiological changes.

M. GARG, MS (Ortho), DNB (Ortho)

B. P. Koirala Institute of Health Sciences Dharan, Nepal.

S. ARORA, MS (Ortho), DNB (Ortho)

University College of Medical Sciences and Guru Teg Bahadur Hospital Delhi, India.

1. Szabó G, Lovász G, Kustos T, Bener A. A prospective comparative analysis of mobility in osteoarthritic knees: does lifestyle have an influence? J Bone Joint Surg [Br] 2000;82-B:1167-9.

2. Hollinshead WH. Anatomy for surgeons - vol. 3. First reprint ed. New York: Harper and Row, 1966:717.

3. Hollinshead WH. Anatomy for surgeons - vol. 3. First reprint ed. New York: Harper and Row, 1966:35.

4. Hollinshead WH. Anatomy for surgeons - vol. 3. First reprint ed. New York: Harper and Row, 1966:24.

\section{Corrections}

\section{Obituary - Alan Joseph Alldred \\ J Bone Joint Surg [Br] 2001;83-B:1207-8.}

It is regretted that the name Alan was incorrectly spelt as Allan throughout the text.
Tauro B, Ackroyd CE, Newman JH, Shah NA. The Lubinus patellofemoral arthroplasty. J Bone Joint Surg [Br] 2001;83-B:696-701.

On page 609 of this article, Figures 3 and 4 have been transposed. 